\title{
Lake restoration influences nutritional quality of algae and consequently Daphnia biomass
}

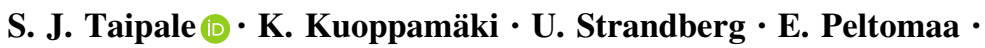 \\ K. Vuorio
}

Received: 31 July 2019/Revised: 26 July 2020/Accepted: 27 August 2020/Published online: 19 September 2020

(C) The Author(s) 2020

\begin{abstract}
Food quality is one of the key factors influencing zooplankton population dynamics. Eutrophication drives phytoplankton communities toward the dominance of cyanobacteria, which means a decrease in the availability of sterols and long-chain polyunsaturated fatty acids (EPA and DHA). The effects of different restoration measures on the nutritional quality of the phytoplankton community and subsequent impacts on zooplankton biomass have rarely been considered. We analyzed the nutritional
\end{abstract}

Guest editors:Tom Jilbert, Raoul-Marie Couture, Brian J. Huser \& Kalevi Salonen/Restoration of eutrophic lakes: current practices and future challenges

Electronic supplementary material The online version of this article (https://doi.org/10.1007/s10750-020-04398-5) contains supplementary material, which is available to authorized users.

\section{S. J. Taipale $(\square)$}

Department of Biological and Environmental Science, University of Jyväskylä, Jyväskylä, Finland

e-mail: sami.taipale@jyu.fi

K. Kuoppamäki · E. Peltomaa

Faculty of Biological and Environmental Sciences,

University of Helsinki, Lahti, Finland

U. Strandberg

Department of Environmental and Biological Sciences,

University of Eastern Finland, Joensuu, Finland quality of phytoplankton in the eutrophic Lake Vesijärvi in southern Finland over a 37-year period, and studied the impacts of two restoration measures, biomanipulation and hypolimnetic aeration, on the abundance of high-quality phytoplankton. We found that biomanipulation had a positive impact on the abundance of taxa synthesizing sterols, EPA, and DHA and, concurrently, on the biomass of the keystone species Daphnia. In contrast, hypolimnetic aeration did not result in such a beneficial outcome, manifested as a decrease in the abundance of Daphnia and frequent phytoplankton blooms dominated by cyanobacteria suggesting reduction in the nutritional quality of food for Daphnia. Our analysis shows that the determination of the nutritional value of algae and the contribution of essential fatty acids and sterols is

\author{
E. Peltomaa \\ Lammi Biological Station, University of Helsinki, \\ Lammi, Finland \\ K. Vuorio \\ Freshwater Centre, Finnish Environment Institute, \\ Helsinki, Finland
}


an effective method to evaluate the success of various restoration measures.

Keywords Nutritional ecology · Freshwater food webs - Daphnia - Fatty acids · Sterols · Amino acids · Cryptophytes $\cdot$ Cyanobacteria

\section{Introduction}

Anthropogenic eutrophication of freshwaters is driven predominantly by phosphorus runoff from agricultural and urban lands (Carpenter, 2008) and typically results in high algal biomass and blooms consisting mainly of cyanobacteria (Jorgensen, 2001). Following tertiary wastewater treatment and the removal of phosphorus from sewage effluent, the concentration of phosphorus has decreased in many European and North American lakes (Jeppesen et al., 2005). Despite this successful control of point source pollution, the 'wicked problem' of eutrophication still persists due to internal phosphorus loading and non-point source pollution from urban and agricultural catchments (Thornton et al., 2013). These maintain the eutrophic state and delay lake recovery (Carpenter, 2003). Several management measures have been applied to accelerate the improvement of water quality and to mitigate cyanobacterial blooms. The most important and efficient measure is the reduction of external nutrient inputs (Huisman et al., 2018), which is a prerequisite for any other restoration measure applied in lakes. However, various genera of cyanobacteria have different total phosphorus (TP) thresholds, and some cyanobacteria species may be abundant at relatively low TP levels (e.g., Vuorio et al., 2020). Thus, this hysteretic response to reduced nutrient concentrations following restoration implies that major additional actions are usually needed to bring a lake closer to the original clear-water state and to prevent harmful cyanobacterial blooms.

One of the most common in-lake restoration measures is biomanipulation by fish removal to decrease phytoplankton biomass through cascading effects of increased zooplankton grazing, especially by keystone species Daphnia, and decreased recycling of nutrients in fish biomass (Søndergaard et al., 2008). Following reduced predation on zooplankton, a shift from the dominance of small cladocerans to larger
Daphnia implies altered nutrient recycling, as higher amount of $\mathrm{P}$ becomes stored in the biomass of daphnids (cf. Hessen et al., 2013). Cyanobacteria species with the capability of $\mathrm{N}$ fixation proliferate at high $\mathrm{P}$ concentrations, so abundant Daphnia can change their competitive advantage over other phytoplankton taxa. Nutrient regeneration and grazing affect autotroph stoichiometry with low biomass but high quality under periods of high consumer biomass and high grazing pressure (Hessen et al., 2013).

Eutrophication and the associated dominance of cyanobacteria have cascading effects on ecosystem functioning, such as impaired trophic transfer of energy and essential micronutrients (Müller-Navarra et al., 2004; Huisman et al., 2018). In addition to changes in phytoplankton composition, advanced eutrophication decreases the content of essential amino acids, $\omega-3$ fatty acids, specifically eicosapentaenoic acids (EPA), and phytosterols in phytoplankton (Taipale et al., 2019b), simply because cyanobacteria do not contain these micronutrients (Müller-Navarra et al., 2004; Persson et al., 2007; Taipale et al., 2016a). Eutrophication also suppresses the relative abundance of cryptophytes and chrysophytes, which are high-quality diet for Daphnia (Watson et al., 1997; Reynolds, 1998; Taipale et al., 2016a, 2019b; Peltomaa et al., 2017). In turn, nontoxic freshwater dinoflagellates (excluding Ceratium species) that usually have a curvilinear response to increasing TP (Watson et al., 1997) are preferential diet for copepods due to their high DHA content but have a twofold effect on Daphnia growth (Peltomaa et al., 2017, Taipale et al., 2019). Additionally, reduced availability of essential amino acids, $\omega-3$ and $\omega-6$ polyunsaturated fatty acids (PUFA), and sterols may limit the growth and reproduction of herbivorous zooplankton (Arts et al., 2009; von Elert and Martin-Creuzburg, 2009; Peltomaa et al., 2017; Schneider et al., 2017) and also impact zooplankton winter survival (Grosbois et al., 2017). Since herbivorous cladocerans cannot bioconvert EPA from shortchain PUFA (ALA, 18:303) efficiently (von Elert 2002; Taipale et al., 2011), they need to obtain this physiologically essential PUFA from their diet.

Increased biomass and/or body size of Daphnia and decreased concentration of chlorophyll $a$ in, at least, some lakes after restoration suggest improved topdown control of phytoplankton (Søndergaard et al. 2008; Anttila et al. 2013). According to the 
quantitative analysis of reported biomanipulation studies by Bernes et al. (2015), the increased biomass of large-bodied Daphnia following biomanipulation may well be explained not only by reduced predation by fish but also by the shift from the predominance of cyanobacteria toward high nutritional quality food for Daphnia. When large Daphnia make up the bulk of zooplankton community, a wider part of the phytoplankton size spectrum is under strong grazing pressure as compared to a community dominated by smallbodied herbivores like Bosmina (Gliwicz, 2003). This favorable change in phytoplankton community structure can result from a change of $\mathrm{N}: \mathrm{P}$-ratio or decreased $\mathrm{pH}$, but also from the fact that large-bodied Daphnia can consume non-filamentous cyanobacteria more efficiently than small-sized Daphnia (e.g., Microcystis; Triest et al., 2015).

The understanding of the importance of high nutritional quality algae vs. predation pressure for successful population development of Daphnia is still poor. Fish removal from Danish lakes increased the abundance of cryptophytes for 10 years, with some exceptions (Søndergaard et al., 2008). This suggests improved nutritional quality of local phytoplankton communities and reduced fish predation; however, the impacts of biomanipulation on the quality of zooplankton diet have not been studied. It has usually been assumed that the top-down regulation of planktivorous fish, rather than bottom-up regulation of phytoplanktonic food, is the main driver of zooplankton community structure, and especially the populations of large-bodied Daphnia. Thus, through these positive feedbacks, increased biomass of large-sized Daphnia might not only be the cause but also the consequence of the decrease in the prevalence of cyanobacteria.

Another common restoration measure other than biomanipulation is hypolimnetic aeration, which attempts to reduce the release of phosphorus from anoxic sediment (e.g., Müller et al., 2012). Air or pure oxygen can be injected into hypolimnion, but another approach is to destratify a lake through artificial circulation of water by pumping oxygen-rich surface water to hypolimnion, resulting in a great increase in temperature at depths that were previously part of the cooler hypolimnion (Cooke et al., 2005). This restoration approach was adopted by managers of Lake Vesijärvi, which was estimated to suffer from high ratio of internal to external P load (ca. 60) (Niemistö et al., 2012). It was assumed that artificial circulation could lead to decreased internal phosphorus cycle in this lake. On the other hand, it can also lead to enhanced availability of phosphorus to phytoplankton (Cooke et al., 2005). Furthermore, deepening thermocline shifts the structure of phytoplankton and zooplankton communities (Cantin et al., 2011). More specifically, because phytoplankton community composition is strongly shaped by physical and chemical factors (Reynolds, 2006; Maileht et al., 2013), increased turbulence and changes in nutrient concentrations may change the relative abundance of various taxa and especially reduce the abundance of cyanobacteria (Webb et al., 1997; Kozak et al., 2017). This can improve the nutritional quality of phytoplankton for zooplankton. To our knowledge, this mechanism of structuring lake food webs following artificial circulation has not received enough attention by the scientific community.

We studied the impacts of biomanipulation and hypolimnetic aeration on the phytoplankton community structure and nutritional quality of phytoplankton as the diet for zooplankton, especially Daphnia and Bosmina. Our study site, Lake Vesijärvi, has been intensively managed with the two management measures to restore the original clear-water state from the eutrophic state characterized by cyanobacterial blooms (Anttila et al., 2013). Several studies have been published on the results of these management measures (Horppila et al., 1998; Anttila et al., 2013; Salmi et al., 2014; Ruuhijärvi et al., 2020; Niemistö et al., 2016), but none of these takes into account that successful bottom-up restoration should increase high nutritional quality algae (cryptophytes, chrysophytes, diatoms, dinoflagellates) to increase zooplankton biomass. We calculated the contribution of $\omega-3$ PUFA, $\omega-6$ PUFA, EPA and DHA, and sterols (sterol index) in autotrophic seston based on laboratory culturing of different phytoplankton genera (see supplemental material, Peltomaa et al., 2017). We hypothesized that biomanipulation increases high nutritional quality algae (cryptophytes, synurophytes (silica-scaled chrysophytes), diatoms) and Daphnia biomass and that hypolimnetic aeration induced mixing enhances non-motile algae other than cyanobacteria, such as diatoms that are mostly high-quality food for zooplankton. 


\section{Materials and methods}

Study site

The eutrophic Lake Vesijärvi (61 $04^{\circ} \mathrm{N}$ and $\left.25^{\circ} 32^{\prime} \mathrm{E}\right)$ is a medium-sized lake $\left(110 \mathrm{~km}^{2}\right)$ with low dissolved organic carbon (DOC) concentration $\left(5-8 \mathrm{mg} \mathrm{C} \mathrm{L}^{-1}\right.$, color ca. $20 \mathrm{mg}$ Pt L-1). The lake consists of several basins, of which our study site, the southernmost Enonselkä basin (mean depth $6.8 \mathrm{~m}$, surface area $26 \mathrm{~km}$ ), became strongly polluted during the $1900 \mathrm{~s}$ by municipal and industrial wastewaters being discharged from the surrounding city of Lahti. Sewage was diverted from the lake in 1976, but it remained eutrophic with frequent cyanobacterial blooms until 1988 (Kairesalo et al. 1999). Large-scale biomanipulation, i.e., mass removal of planktivorous fish, was conducted in 1989-1993 (Horppila et al., 1998; Kairesalo et al., 1999; Kairesalo \& Vakkilainen, 2004). This major restoration effort was followed by the collapse of cyanobacterial biomass, which doubled water clarity (Kairesalo \& Vakkilainen, 2004) and increased the body size of Daphnia (Anttila et al., 2013). However, the improved water quality turned out to be only temporary, as high cyanobacterial biomasses reappeared in the Enonselkä basin in the 21 st century ( $>50 \%$ of all phytoplankton in average of summer months of 2001, 2002, 2005, 2007, 2009, 2013, 2016), despite the continuous management fishing (Kairesalo \& Vakkilainen, 2004). This suggests that external non-point source loading to the lake was still too high and beyond the threshold for high internal loading ( $c f$. Andersen et al., 2008). To improve water quality, hypolimnetic aeration was turned on in autumn 2009 and has been continued yearly during stratification periods. The aim of this artificial circulation of oxygen-rich surface water to hypolimnion is to reduce internal loading of phosphorus from sediment. For the purposes of our study, we divided the years 1979-2016 in five distinct stages based on cyanobacterial bloom occasions and lake management efforts (Table 1) to find out if restoration affects the nutritional quality of algae and the biomass of Daphnia and Bosmina.

\section{Phytoplankton composition}

Phytoplankton composition and abundance in Enonselkä basin (from the deepest point of the basin,
Lankiluoto) were taken from the database of the Finnish Environment Institute. The same source was used to get data on total phosphorus concentrations. Phytoplankton abundances at genus level were converted to biovolumes according to appropriate geometric formulae, which in turn was converted to biomass by assuming that phytoplankton density equals water density $\left(1 \mathrm{~g} \mathrm{~cm}^{-3}\right)$. Biovolumes were converted to carbon content according to MendenDeuer \& Lessard (2000) and used in statistical analysis. Phytoplankton were divided into non-EPA and non-DHA-synthesizing (green algae, desmids, cyanobacteria), EPA-synthesizing (cryptophytes, dinoflagellates, chrysophytes, diatoms, raphidophytes), and DHA-synthesizing (cryptophytes, dinoflagellates, chrysophytes, euglenoids) taxa, similarly to our previous study (Taipale et al., 2016a).

The contribution of EPA and DHA

The contribution of EPA and DHA in the phytoplankton community composition was estimated based on the genus-specific fatty acid composition, so-called reference data obtained from cultured algae (Ahlgren et al., 1992; Volkman et al., 1999; Boechat et al., 2007; Burns et al., 2011; Bigelow et al., 2013; Taipale et al., 2013, 2016b; Slocombe et al., 2015; Peltomaa et al., 2019; Strandberg et al. 2015; Soares et al., 2019). The full genus-specific fatty acid data used in the estimation is found in the Supplementary Material. In cases where the reference data did not contain fatty acid profile for a specific genus, the fatty acid profile of the phylogenetically closest relative was used. Algal fatty acid composition is known to be phylogenetically determined and the effects of environmental factors, e.g., temperature and nutrient levels are less pronounced (Galloway \& Winder, 2015). The contribution of EPA or DHA in each taxon in the phytoplankton sample was estimated by calculating the percentage of EPA or DHA from the algae percentage in one sample. For example, the percentage of Rhodomonas was $3.1 \%$ in the sample collected on the 28th of July, 2008 and in Rhodomonas the proportion of EPA from all fatty acid is $12.5 \%$ (obtained from the reference library and constant for Rhodomonas), thus about $0.4 \%$ of the fatty acids in the phytoplankton was EPA from Rhodomonas $(0.031 \times 0.125=0.0038$, i.e., $0.4 \%)$. The same calculation was made for each taxon to achieve the 
Table 1 Years 1979-2016 of Lake Vesijärvi (Enonselkä Basin) divided into five stages based on lake restoration measures and cyanobacteria bloom occurrence

\begin{tabular}{llll}
\hline Stage & Years & $\begin{array}{l}\text { TP }(\mu \mathrm{g} \mathrm{P} \\
\left.1^{-1}\right)\end{array}$ & Notices \\
\hline First blooming & $1979-1988$ & $43.6 \pm 4.2^{\mathrm{b}}$ & One oxygenation station 1979-1984, high abundance of cyanobacteria \\
Biomanipulation & $1989-1993$ & $37.9 \pm 5.6^{\mathrm{b}}$ & Removal of cyprinid fish, planting \\
Clear-water & $1994-1999$ & $27.0 \pm 2.9^{\mathrm{a}}$ & Clear-water, no cyanobacteria blooms \\
Second blooming & $2000-2009$ & $26.5 \pm 3.3^{\mathrm{a}}$ & $\begin{array}{l}\text { Cyanobacterial blooms excluding some years } \\
\text { Hypolimnetic }\end{array}$ \\
$\begin{array}{l}\text { aeration } \\
\text { 2010-2016 }\end{array}$ & $25.2 \pm 3.1^{\mathrm{a}}$ & $\begin{array}{c}\text { Period of aeration of 8 oxygenators varied from couple of weeks to whole } \\
\text { summer }\end{array}$ \\
\hline
\end{tabular}

percentage of EPA (or DHA) in the whole phytoplankton sample. Subsequently, the contributions of EPA (or DHA) from different algal taxa were summed to achieve an estimate of EPA (or DHA) contribution in the entire sample. Percentages were directly summed up since they came from the same group, i.e., phytoplankton assembly.

\section{Sterol index}

Sterol index was calculated as in Peltomaa et al. (2017). We used the sterol content ( $\mu$ g STE mg $\mathrm{C}^{-1}$ ) of cultured phytoplankton strains to calculate the phytoplankton-derived concentration $\left(\mu \mathrm{g} \mathrm{STE} 1^{-1}\right)$ of analyzed sterols in Lake Vesijärvi based on phytoplankton carbon biomass $\left(\mu \mathrm{g} \mathrm{C} 1^{-1}\right)$. The content $(\mu \mathrm{g}$ STE $\mathrm{mg}^{-1} \mathrm{C}$ ) of each sterol in one sample was based on the cumulative sum of each phytoplankton genus:

$$
\begin{aligned}
\sum \mu g S T E m g C= & \frac{S T E_{a} * C B M_{a}}{T C B M}+\frac{S T E_{b} * C B M_{b}}{T C B M} \\
& +\ldots+\frac{S T E_{n} * C B M_{n}}{T C B M}
\end{aligned}
$$

where STE denotes the content of sterol (sterol in $\mathrm{mg}$ C) and $C B M$ the carbon biomass $\left(\mu \mathrm{g} \mathrm{C} 1^{-1}\right)$ of each phytoplankton genus $(\mathrm{a}, \mathrm{b}, \ldots, \mathrm{n})$, and TCBM denotes the phytoplankton total carbon biomass $\left(\mu \mathrm{g} \mathrm{C}^{-1}\right)$ of the corresponding lake sample. If the sterol content for a specific genus was not available, the average sterol content of corresponding phytoplankton class was used for the calculation.

Sterol index for each sample was calculated by dividing the total sum of each sterol ( $\mu \mathrm{g} \mathrm{STE} / \mathrm{mg} \mathrm{C}$ ) by the threshold (Martin-Creuzburg et al., 2014):
Sterol index $=\frac{S T E_{a}}{T H_{a}}+\frac{S T E_{b}}{T H_{b}}+\ldots+\frac{S T E_{n} *}{T H_{n}}$,

where STE is sterol content ( $\mu \mathrm{g}$ STE $\mathrm{mg} \mathrm{C}^{-1}$ ) of each sterol $(a, b, \ldots, n)$ in the lake sample and $\mathrm{TH}$ is corresponding threshold value for each sterol $(a, b, \ldots$, $n)$. Sterol index values $<1$ were considered as limiting.

The threshold values for the sterol index determinations were obtained from Martin-Creuzburg et al. (2014) who determined dietary threshold concentrations for ten different phytoplankton-derived sterols. We categorized sterols into two groups: (1) low threshold sterols with values similar or even lower than cholesterol and (2) high threshold sterols with values higher than cholesterol. Thresholds were $3.9 \mu \mathrm{g}$ STE $\mathrm{mg} \mathrm{C}^{-1}$ for fucosterol, $5.48 \mu \mathrm{g}$ STE mg $\mathrm{C}^{-1}$ for brassicasterol, $8.25 \mu \mathrm{g}$ STE $\mathrm{mg} \mathrm{C}^{-1}$ for stigmasterol, $15.0 \mu \mathrm{g}$ STE $\mathrm{mg} \mathrm{C}^{-1}$ for campesterol, and $21.7 \mu \mathrm{g} \mathrm{STE} \mathrm{mg} \mathrm{C}^{-1}$ for fungisterol, chondrillasterol, dihydrochondrillasterol and schottenol, and $22.0 \mu \mathrm{g} \mathrm{STE} \mathrm{mg} \mathrm{C}^{-1}$ for b-sitosterol. For untested sterols we used the thresholds of the most similar sterol based on the number of double bonds and carbon chain length.

\section{Zooplankton biomass}

Zooplankton biomass comprises the sum of all Daphnia species (D. cristata, D. longiremis, D. cucullata, D. galeata) and Bosmina (B. crassicornis, B. longispina, B. longirostris) in the deepest part $(30 \mathrm{~m})$ of the Enonselkä basin (Lankiluoto), measured at the University of Helsinki. Daphnia biomass was counted in only two years (1991 and 1993) during the 
biomanipulation stage and thus we combined stages of biomanipulation and clear-water stages (zooplankton samples counted in 1994, 1997 and 1999) as one group (called as clear-water stage in Fig. 3C). Daphnia biomass was counted eight times during the second blooming stage (2001-2006, 2009) and three times (2011, 2013, 2015, 2016) during the hypolimnetic aeration. We used the average of summer months (June-August) and full seasonal data (May-October) in the statistical analyses. Cladoceran biomasses were calculated from length-carbon regressions like described in Vakkilainen et al. (2004).

\section{Data analysis}

We used PERMANOVA (Primer 7) analysis and Bray Curtis similarity to compare phytoplankton community structure at genus level $\left(\mu \mathrm{g} \mathrm{C} \mathrm{L}^{-1}\right)$ using the five lake stages and month as factors. We used non-metric multidimensional scaling NMDS (Primer 7) to separate phytoplankton communities of the stages. The interactions between MDS1 and MDS2 and phytoplankton biomass at genus level were analyzed with Spearman correlation analysis. The differences in variances (the mean distance to the centroid) of the phytoplankton community were examined with analysis of multivariate homogeneity of group dispersions (PERMIDISP, Primer 7). Similarity percentages (SIMPER, Primer 7) were used to identify the characteristic phytoplankton genus of each stage and to find out phytoplankton taxa for dissimilarities between stages.

We used PERMANOVA as univariate analysis for comparing the summer (June, July, August) mean values of the sterol-synthesizing, non-EPA/DHA, EPA-synthesizing and DHA-synthesizing taxa, sterol index, the contribution of $\omega-3$ PUFA, $\omega-6$ PUFA, EPA and DHA, and the biomass of Bosmina and Daphnia among the five stages, having lake stage as a factor. Pairwise PERMANOVA was used to explore if the stages differ statistically from each other and identify possible differences. Since we used PERMANOVA as univariate analysis, we used Euclidean distance as resemblance matrix (Anderson 2017). Additionally, we used monthly averages of each response variable with lake stage and month as factors in two-factor PERMANOVA.

\section{Results}

Phytoplankton community structure among different stages

Total phosphorus concentrations (TP) were significantly higher during the first blooming and biomanipulation stage (ANOVA: $F_{4,37}=38.8, P<0.0001$ ) in relation to any other stages (Table 1). In all, 62 phytoplankton genera occurred during at least 15 of the 38 years studied and these genera were used in further statistical analyses. According to the PERMANOVA, phytoplankton community structure at genus

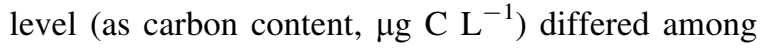
stages $\left(F_{4,37}=4.14, P=0.001\right)$. Nevertheless, phytoplankton community of the second blooming stage did not differ from communities during the stages of clear-water or the hypolimnetic aeration (hereafter referred to as aeration stage). Stage alone explained $33 \%$ of differences in the phytoplankton community structure. When month was used as an additional factor for phytoplankton community analysis in PERMANOVA, stage $\left(F_{4,186}=2.49, \quad P=0.046\right)$ explained only $5 \%$ and month $\left(F_{7,186}=0.37\right.$, $P=0.001) 1 \%$ of variation in phytoplankton community structure. Pairwise comparison $(P<0.05)$ showed that the clear-water stage differed from the stages of first blooming, biomanipulation, and aeration. Additionally, the first blooming stage differed from the biomanipulation stage.

Analysis of NMDS separately clustered phytoplankton communities (as $\mu \mathrm{g} \mathrm{C} \mathrm{L}^{-1}$ ) of different stages (Fig. 1A) along axes of MDS1 and MDS2 excluding the second blooming stage which overlapped with all stages. MDS1 correlated positively with non-EPA and non-DHA-synthesizing phytoplankton taxa (Pearson $r=0.90, P<0.001$ ) and negatively with EPA-synthesizing taxa (Pearson $r=-0.90, P<0.001)$. MDS1 correlated positively most strongly with the genera Planktothrix, Pseudanabaena, Aphanizomenon and Monomastix, and negatively with Mallomonas, Pseudopedinella, Dinobryon, and Asterionella (Table 2). MDS2 correlated positively with many taxa (e.g., Microcystis, Fragilaria, Table 2), but negatively only with Planktothrix. PERMDISP indicated that there was significant unequal dispersion among the stages $\left(F_{4,33}=4.20\right.$; $P<0.028$, Fig. 1B), with clear stage having lower dispersion from centroid than others. However, 


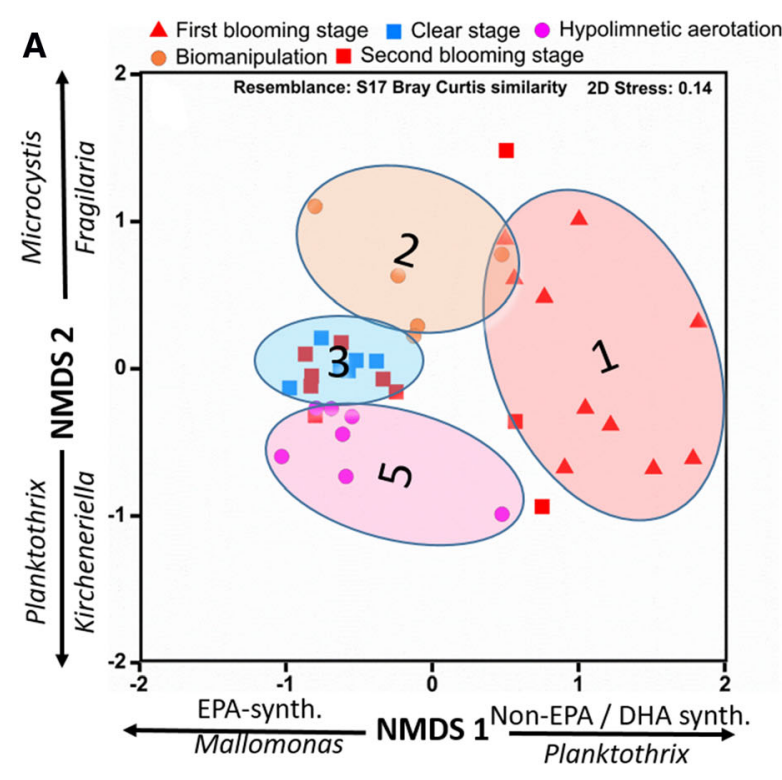

Fig. 1 A The output of non-metric MDS of quantitative phytoplankton community structure $\left(\mu \mathrm{g} \mathrm{C} 1^{-1}\right)$. The strongest Spearman correlations are represented above the arrows. Remaining correlations are presented in Table 3. Numbers

pairwise comparison showed that dispersion of the clear stage differed statistically only from the first and second blooming stage. Analysis of similarity (SIMPER) showed highest similarity among phytoplankton community of the years of the clear stage which according to similarity followed the order aeration stage $>$ first blooming stage $>$ second blooming stage (Table 3). Tabellaria, Cryptomonas, Rhodomonas, Mallomonas and Ceratium formed together $60 \%$ of the cumulative similarity on the clear stage, whereas high biomasses of Planktothrix and Aphanizomenon formed most similarity of first blooming stage (Table 3). Highest dissimilarity was found between the first blooming stage and other stages (dissimilarity 77-87\%) as a result of higher biomasses of Planktothrix and Aphanizomenon in the first blooming stage compared to any of the other stages.

Phytoplankton quality at different stages

According to the PERMANOVA (Pseudo$\left.F_{4,37}=11.21, P=0.001\right)$, the contribution of sterolsynthesizing taxa differed among stages (Fig. 2A), and stage as a factor explained $57.6 \%$ of all variation. The contribution of sterol-synthesizing taxa was lower in the first blooming than in any other stage

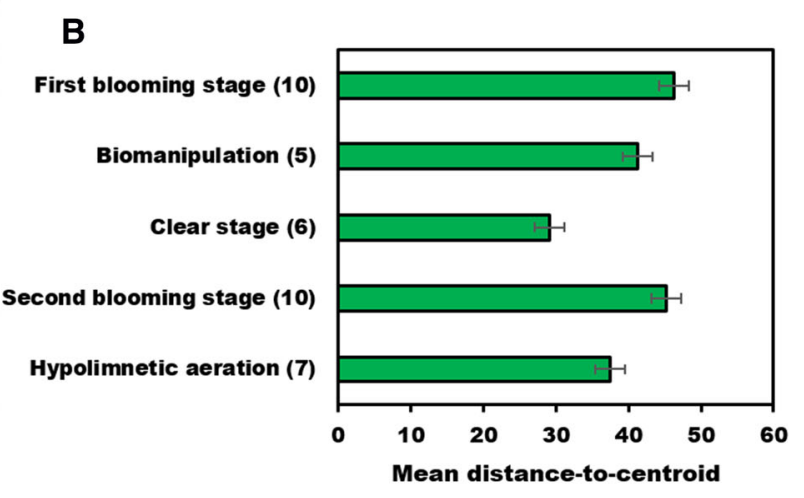

inside circles refer to different stages (see Table 1). B Distance from centroids (Distance-based test for homogeneity of multivariate dispersions) of phytoplankton community structure in different stages. Number of $n$ is in parenthesis

( $t=4.29-14.26, P=0.001-0.005)$. The contribution of sterol-synthesizing taxa was significantly higher ( $t=1.70-2.11 P=0.027-0.042$ ) during the clearwater stage than during the biomanipulation stage or the aeration stage. According to the pairwise PERMANOVA, the clear-water stage and the second blooming stage did not differ from each other $(P>0.073)$. The contribution of non-EPA and nonDHA-synthesizing taxa differed among stages (PERMANOVA Pseudo- $F_{4,37}=10.26, \quad P=0.001$, Fig. 2A) and the stage explained $55.4 \%$ of all variation. Pairwise PERMANOVA $(t=3.12-10.17$, $P=0.001-0.007)$ showed that the first blooming stage had significantly higher contribution of non-EPA and non-DHA-synthesizing taxa in relation to any other stage. The contribution of non-EPA and non-DHAsynthesizing taxa was the lowest during the clearwater stage, which significantly differed from both the biomanipulation stage and the aeration stage $(t=1.89$, $P=0.07)$. The contribution of EPA- (PERMANOVA: Pseudo- $\left.F_{4,37}=10.1, P=0.001\right)$ and DHA-synthesizing taxa (PERMANOVA: Pseudo- $F_{4,37}=9.85$, $P=0.001$, Fig. 2A) was lowest during the first blooming stage. The contribution of EPA- and DHAsynthesizing taxa was highest $(81 \pm 6.9 \%$ and $55 \pm 8.6 \%$ of all phytoplankton, respectively) during 
Table 2 Pearson correlation between different phytoplankton genus and axes of MDS1 and MDS2

\begin{tabular}{|c|c|c|c|}
\hline Group/Class & Genus & MDS1 & MDS2 \\
\hline Non-EPA and non-DHA synth & Chroococcus & -0.1 & $0.362 *$ \\
\hline \multirow[t]{8}{*}{ Cyanobacteria } & Gomphosphaeria & $0.323 *$ & 0.2 \\
\hline & Microcystis & 0.2 & $0.516 * *$ \\
\hline & Aphanizomenon & $0.495 * *$ & $0.417 * *$ \\
\hline & Dolichospermum & $0.444 * *$ & $0.397 *$ \\
\hline & Planktothrix & $0.704 * *$ & $-0.352 *$ \\
\hline & Pseudanabaena & $0.562 * *$ & -0.1 \\
\hline & Snowella & 0.0 & $0.485 * *$ \\
\hline & Woronichinia & 0.2 & $0.373 *$ \\
\hline \multirow[t]{6}{*}{ Green algae and desmids } & Pediastrum & -0.2 & $0.418 * *$ \\
\hline & Closterium & 0.1 & $0.393 *$ \\
\hline & Cosmarium & -0.1 & $0.338 *$ \\
\hline & Staurastrum & 0.0 & $0.439 * *$ \\
\hline & Botryococcus & -0.2 & $0.379 *$ \\
\hline & Monomastix & $0.528 * *$ & 0.3 \\
\hline EPA and DHA synth. & Dinobryon & $-0.401 *$ & 0.2 \\
\hline \multirow[t]{2}{*}{ Chrysophytes } & Pseudopedinella & $-0.473 * *$ & -0.2 \\
\hline & Chrysochromulina & $-0.391 *$ & -0.1 \\
\hline Synyrophytes & Mallomonas & $-0.397 *$ & -0.1 \\
\hline Cryptophytes & Cryptomonas & $0.485^{* *}$ & 0.2 \\
\hline \multirow[t]{3}{*}{ Diatoms } & Fragilaria & 0.1 & $0.515^{* *}$ \\
\hline & Asterionella & $-0.324 *$ & -0.1 \\
\hline & Cyclotella & $0.376^{*}$ & -0.1 \\
\hline \multirow[t]{3}{*}{ Dinoflagellates } & Peridiniopsis & 0.1 & $0.362^{*}$ \\
\hline & Glenodinium & 0.2 & $0.344 *$ \\
\hline & Peridinium & -0.1 & $0.340 *$ \\
\hline Euglenoids & Trachelomonas & $0.598 * *$ & 0.2 \\
\hline
\end{tabular}

the clear-water stage. The contribution of EPAsynthesizing taxa was higher than during the aeration stage $(t=2.03, P=0.026)$ and the contribution of DHA-synthesizing taxa was higher than during any other stage $(t=1.77-1.93, P=0.03-0.044)$. Stage alone explained $55.0 \%$ and $54.3 \%$ of variation in the contribution of EPA- and DHA-synthesizing taxa, respectively.

The contribution of $\omega-3$ and $\omega-6$ PUFA and sterol index at different stages

Based on phytoplankton composition at genus level, we calculated (Taipale et al., 2016) the contribution of $\omega-3$ and $\omega-6$ PUFA of all FAs for each sampling date using summer averages (Fig. 2B) and monthly averages (Fig. 3). The contribution of $\omega-3$ PUFA was
$33.2 \pm 5.1 \%$ of all FA and did not vary among stages (PERMANOVA: Pseudo- $F_{4,37}=1.54, P=0.213$ ), whereas the contribution of $\omega-6$ PUFA varied among treatments (PERMANOVA: Pseudo- $F_{4}, 37=7.62$, $P=0.001)$. The contribution of $\omega-6$ PUFA was lowest in the first blooming stage (Pairwise PERMANOVA: $t=3.47-5.21, P=0.001-0.004)$ and highest in the biomanipulation stage (Pairwise PERMANOVA: $t=2.72-2.92, P=0.014-0.015)$. However, the contribution of $\omega-6$ PUFA was equally low during stages of first blooming and aeration (Pairwise PERMANOVA: $t=1.47, P=0.171)$. Stage as a factor explained $48 \%$ of variation in $\omega-6$ PUFA. The contribution of EPA and DHA followed a parabolic trend, having the highest contribution during the clearwater stage $(9.6 \pm 1.8 \%$ and $4.5 \pm 1.2 \%$, Fig. $2 \mathrm{~B})$. According to the PERMANOVA, the contribution of 
Table 3 Similarity percentages (SIMPER) of phytoplankton community structure of different stages

\begin{tabular}{|c|c|c|c|}
\hline Stage / Genus & Mean & Similarity & Contrib\% \\
\hline First Blooming Stage & & 32.5 & \\
\hline Planktothrix & 306.98 & 11.85 & 36.45 \\
\hline Aphanizomenon & 151.65 & 6.07 & 18.67 \\
\hline Cryptomonas & 40.72 & 3.92 & 12.07 \\
\hline Dolichospermum & 101.26 & 3.07 & 9.44 \\
\hline Biomanipulation & & 34.23 & \\
\hline Cryptomonas & 40.58 & 7.66 & 22.37 \\
\hline Dolichospermum & 31.96 & 4.5 & 13.15 \\
\hline Microcystis & 28.71 & 3.94 & 11.52 \\
\hline Tabellaria & 13.38 & 2.24 & 6.54 \\
\hline Clear Stage & & 55.45 & \\
\hline Tabellaria & 22.59 & 10.61 & 19.14 \\
\hline Cryptomonas & 19.82 & 10.3 & 18.58 \\
\hline Rhodomonas & 11.03 & 5.06 & 9.12 \\
\hline Mallomonas & 7.69 & 3.74 & 6.74 \\
\hline Second Blooming Stage & & 32.9 & \\
\hline Cryptomonas & 15.64 & 7.29 & 22.15 \\
\hline Tabellaria & 23.93 & 6.26 & 19.02 \\
\hline Rhodomonas & 7.74 & 2.5 & 7.61 \\
\hline Ceratium & 8.87 & 2.25 & 6.83 \\
\hline Hypolimnetic aeration & & 42.43 & \\
\hline Rhodomonas & 14.4 & 10.99 & 25.91 \\
\hline Cryptomonas & 8.81 & 6.89 & 16.23 \\
\hline Dolichospermum & 7.36 & 4.58 & 10.81 \\
\hline Asterionella & 6.16 & 2.67 & 6.3 \\
\hline
\end{tabular}

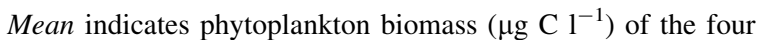
genera that contributed most to the similarity of each stage

EPA (Pseudo- $F_{4}, 37=6.52, P=0.002$ ) and DHA (Pseudo- $F_{4}, \quad 37=3.36, P=0.025$ ) varied significantly among stages, and stage as a factor explained $44 \%$ and $29 \%$ of variation, respectively. Pairwise comparison showed that the contribution of EPA $(t=3.25-7.24, P=0.001-0.006)$ was higher during the biomanipulation, clear-water, and second blooming stages than during the first blooming stage. The contribution of DHA ( $t=2.3-3.0, P=0.008-0.031)$ was higher in clear-water and second blooming stage than in the first blooming stage. The contribution of DHA was equally low during the stages of the first blooming, biomanipulation, and the aeration. Sterol index differed among stages (PERMANOVA: Pseudo- $F_{4,37}=9.94, P=0.001$ ), being lowest (Pairwise PERMANOVA: $t=3.6-5.4, P=0.001-0.003$ ) in the first blooming stage and highest (Pairwise PERMANOVA: $t=2.2-2.6, P=0.021-0.033$ ) during the biomanipulation stage (Fig. 2C).

Seasonal patterns of the contribution of $\omega-3$ and $\omega$ 6 PUFA and sterol index

Monthly averages of the contribution of $\omega-3$ and $\omega-6$ PUFA to all fatty acids (Fig. 3) differed significantly among stages (PERMANOVA: Pseudo- $F_{3,182}=2.13$, $P=0.084$, Table 4 ) and among months (PERMANOVA: Pseudo- $F_{3}, 182=2.13, P=0.084$, Table 5). However, stage and month explained only $6-11 \%$ and 9-11\%, respectively, of the variation in $\omega-3$ and $\omega-6$ PUFA contribution. Nevertheless, it is notable that the contribution of $\omega$-3 PUFA differed between the first blooming stage, the biomanipulation stage and the clear-water stage (Table 4). Additionally, the biomanipulation stage differed from the clear-water stage (Table 4). Month explained $14 \%$ and $15 \%$ of variance of the contribution of EPA (PERMANOVA: Pseudo$\left.F_{7,187}=5.23, P=0.001\right)$ and DHA (PERMANOVA: Pseudo- $\left.F_{7}, 187=6.16, P=0.002\right)$. Stage explained $10.6 \%$ and $7.7 \%$ of variance of EPA (PERMANOVA: Pseudo- $\left.F_{7,187}=7.0, P=0.001\right)$ and DHA (PERMANOVA: Pseudo- $F_{7}, 187=5.40, p=0.002$ ), respectively. Pairwise comparison showed that the first blooming stage had lower contribution of EPA throughout the open-water season than any other stage (Table 4, Fig. 3). The contribution of EPA was higher during the clear-water stage than during any other stage (Table 4). The contribution of DHA differed between the first blooming and all other stages (Table 4). The clear-water stage differed from the aeration stage when the whole growing season (MayOctober) was taken into account (Table 4).

Sterol index showed a more apparent seasonal trend during the biomanipulation stage than in any other stage (Fig. 4A). When month and stage were both used in a two-factor PERMANOVA analysis, they explained $4.0 \%$ and $12.2 \%$ of variance, respectively. However, sterol index differed significantly only among stages (PERMANOVA: Pseudo$\left.F_{4,182}=7.14, P=0.002\right)$ and not among months (PERMANOVA: Pseudo- $F_{5}, 182=1.88, p=0.11$ ). Pairwise PERMANOVA revealed that the sterol index was lower during any month of the first blooming stage when compared to months during other stages (Table 4). 

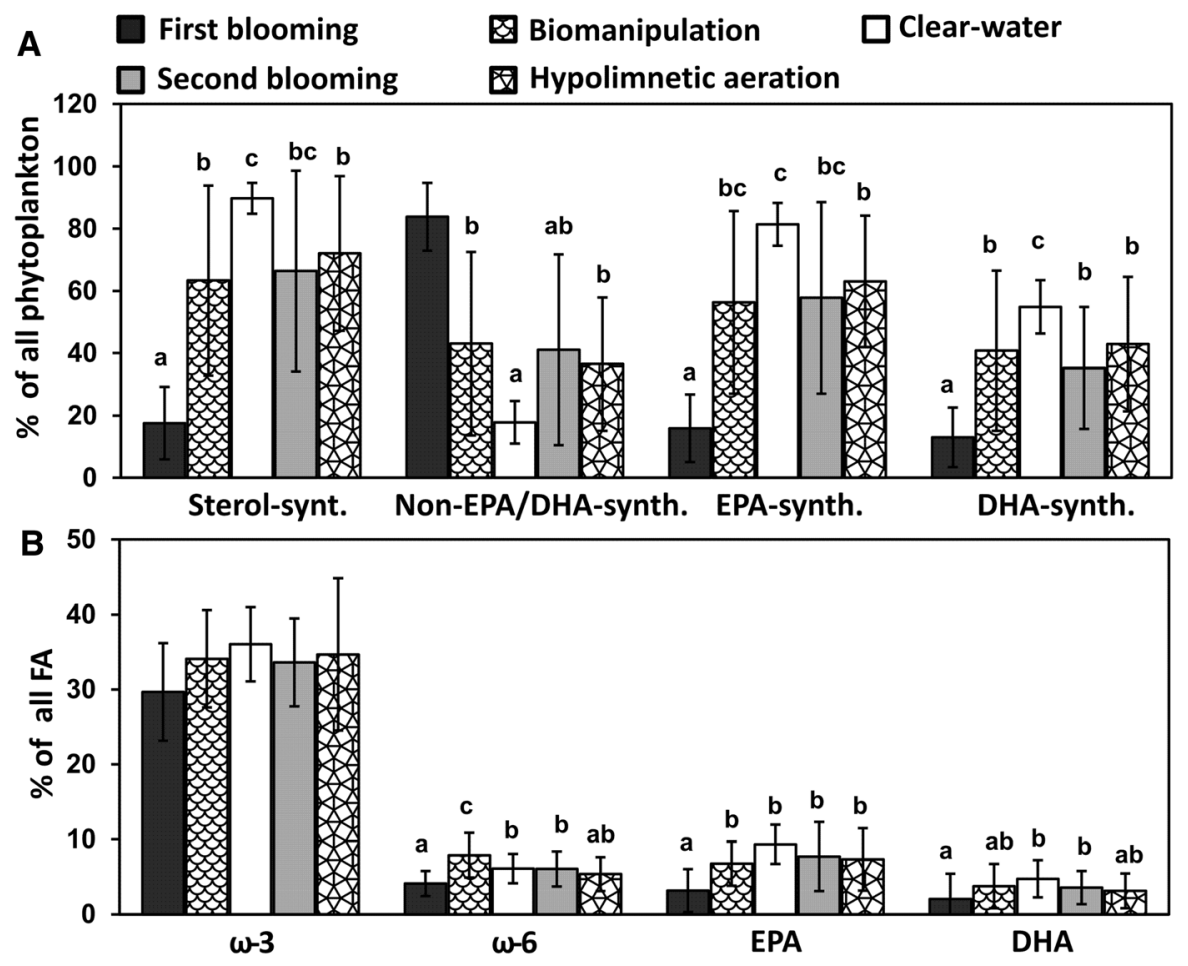

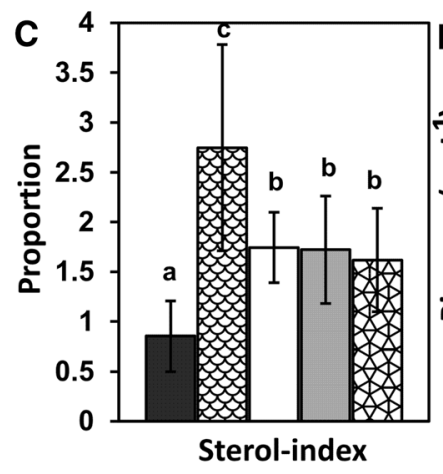

Fig. 2 A The contribution (average of summer months) of sterol-, non-EPA- and non-DHA-, EPA- and DHA-synthesizing phytoplankton in different stages. B The contribution of $\omega-3$ PUFA, $\omega-6$ PUFA, EPA, and DHA of all fatty acids, C Sterol

\section{Relationship between Daphnia and Bosmina}

biomass with the biochemical parameters

The relationship between the total biomass of Daphnia and Bosmina with sterol index was significant $\left(F_{1,15}=7.29, r^{2}=0.32, P=0.014\right)$, and this regression was even stronger $\left(F_{1,15}=14.14, r^{2}=0.52\right.$, $P=0.002$ ) when the highest cladoceran biomasses were excluded from the analysis (Fig. 5). Regression between the contribution of $\omega-6$ PUFA and the biomass of Daphnia and Bosmina was also significant index, and Bosmina and Daphnia biomasses in different stages. Different letters refer to the statistical difference $(p<0.05$, $a<b<c$ ) by pairwise PERMANOVA

$\left(F_{1,15}=5.22, \quad r^{2}=0.27, \quad P=0.038\right)$, though $\omega-6$ PUFA did not explain variation in the biomasses as well as sterol index. Among the contribution of $\omega-3$ PUFA, EPA and DHA, the regression between the cladocerans and DHA was the strongest and marginally significant at 0.05 level $\left(F_{1,15}=4.25, r^{2}=0.23\right.$, $p=0.058)$. The contribution of $\omega-3$ PUFA $\left(F_{1,15}=0.94, \quad r^{2}=0.063, \quad P=0.349\right) \quad$ and EPA $\left(F_{1,15}=2.08, r^{2}=0.13, P=0.171\right)$ was not related to the biomasses of Daphnia and Bosmina. 

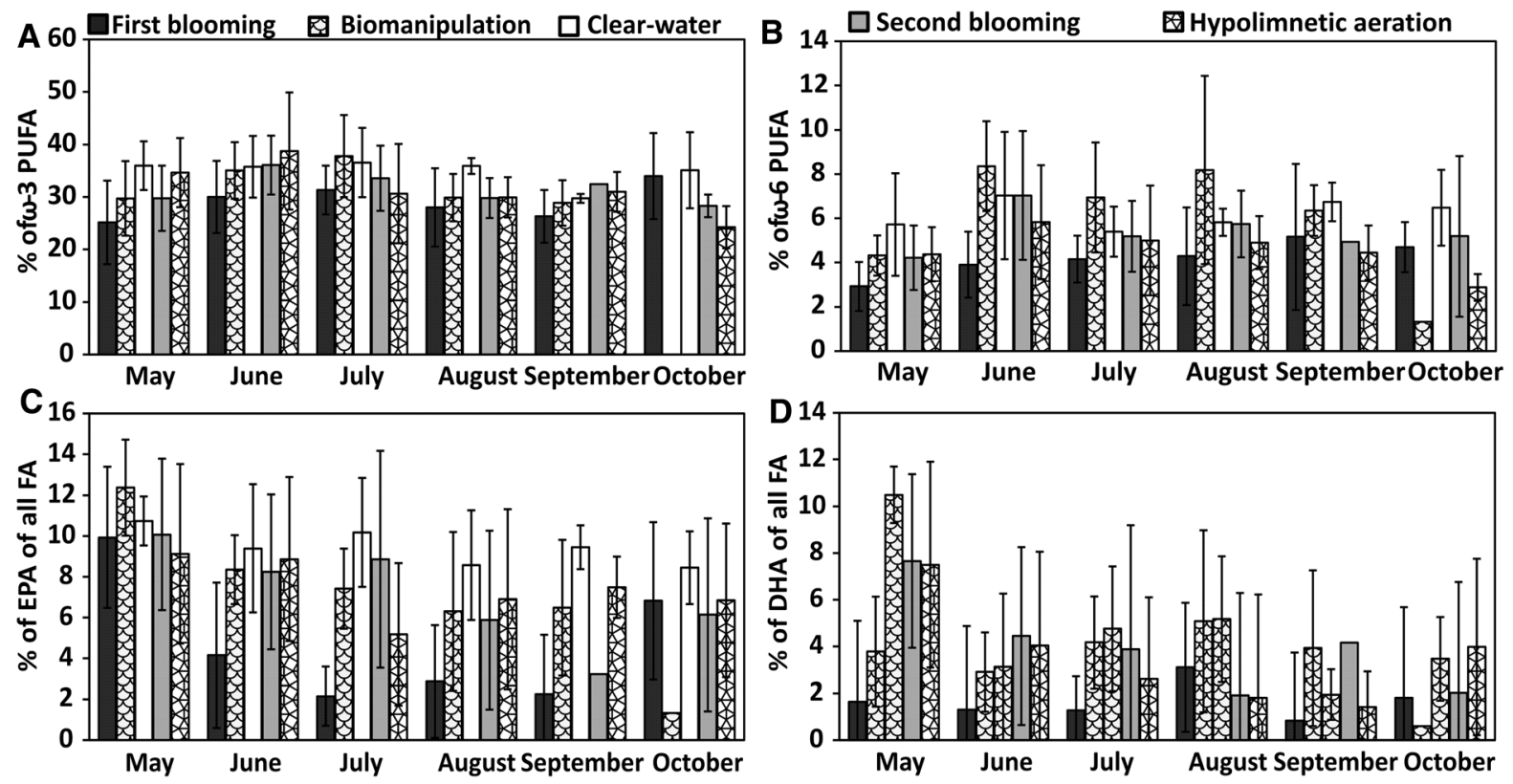

Fig. 3 A The contribution of $\omega-3$ PUFA, B $\omega-6$ PUFA, C EPA, D DHA during open-water months in different stages. See statistical difference among stages and months from Tables 4 and 5

Changes in Daphnia and Bosmina biomass over different stages

Since zooplankton studies started only in 1991, after two years of intensive management fishing, we did not have any Daphnia or Bosmina biomass data from the first blooming stage, and only two years of data was available during the biomanipulation stage. Therefore, the biomanipulation stage was merged with the clearwater stage in their biomass analysis. The biomass of Bosmina was almost equal during the stages of biomanipulation, the clear-water, and the second blooming. The summer average biomass of Bosmina was higher during the biomanipulation stage and the clear-water stage $\left(30.5 \pm 11.5 \mu \mathrm{g} \mathrm{L}^{-1}\right)$ and the second blooming stage $\left(30.1 \pm 13.8 \mu \mathrm{g} \mathrm{L}^{-1}\right)$ than during aeration $\left(23.9 .1 \pm 14.1 \mu \mathrm{g} \mathrm{L}^{-1}\right)$, but due to the high standard deviations this difference was not significant (PERMANOVA: $F_{2,15}=0.36, P=0.73$ ). Daphnia biomass was two times higher during the summers of biomanipulation and the clear-water stage than during aeration (PERMANOVA: $F_{2,15}=6.8, P=0.009$ ). Pairwise PERMANOVA showed that Daphnia biomass was also higher $(t=2.4-4.3, P=0.018-0.043$ ) during the second blooming stage than during the years of aeration. According to the PERMANOVA analysis, stage explained $51 \%$ of the variation in the Daphnia biomass.

According to the two-factor PERMANOVA (stage $\mathrm{x}$ month), Bosmina biomass differed among months (PERMANOVA: $F_{5,94}=18.31, P=0.001$ ), but not among stages (PERMANOVA: $F_{2}, 94=6.8$, $P=0.009)$. Month explained $50.1 \%$ of Bosmina biomass variation (Tables 4, 5). Two-factor PERMANOVA found difference among stages (PERMANOVA: $\left.\quad F_{2}, \quad 94=6.35, \quad P=0.003\right)$ and month (PERMANOVA: $F_{5}, 94=10.97, p=0.001$ ) when monthly averages of Daphnia biomass were used in analysis. Month and stage explained $32.4 \%$ and $7.5 \%$ of the variation in Daphnia biomass, respectively. Pairwise PERMANOVA showed a significant difference among the stages of aeration, clear-water, and second blooming (Table 4).

\section{Discussion}

Biomanipulation and hypolimnetic aeration alter phytoplankton community structure

To our knowledge, the abundance of high nutritional value phytoplankton has not been taken into 

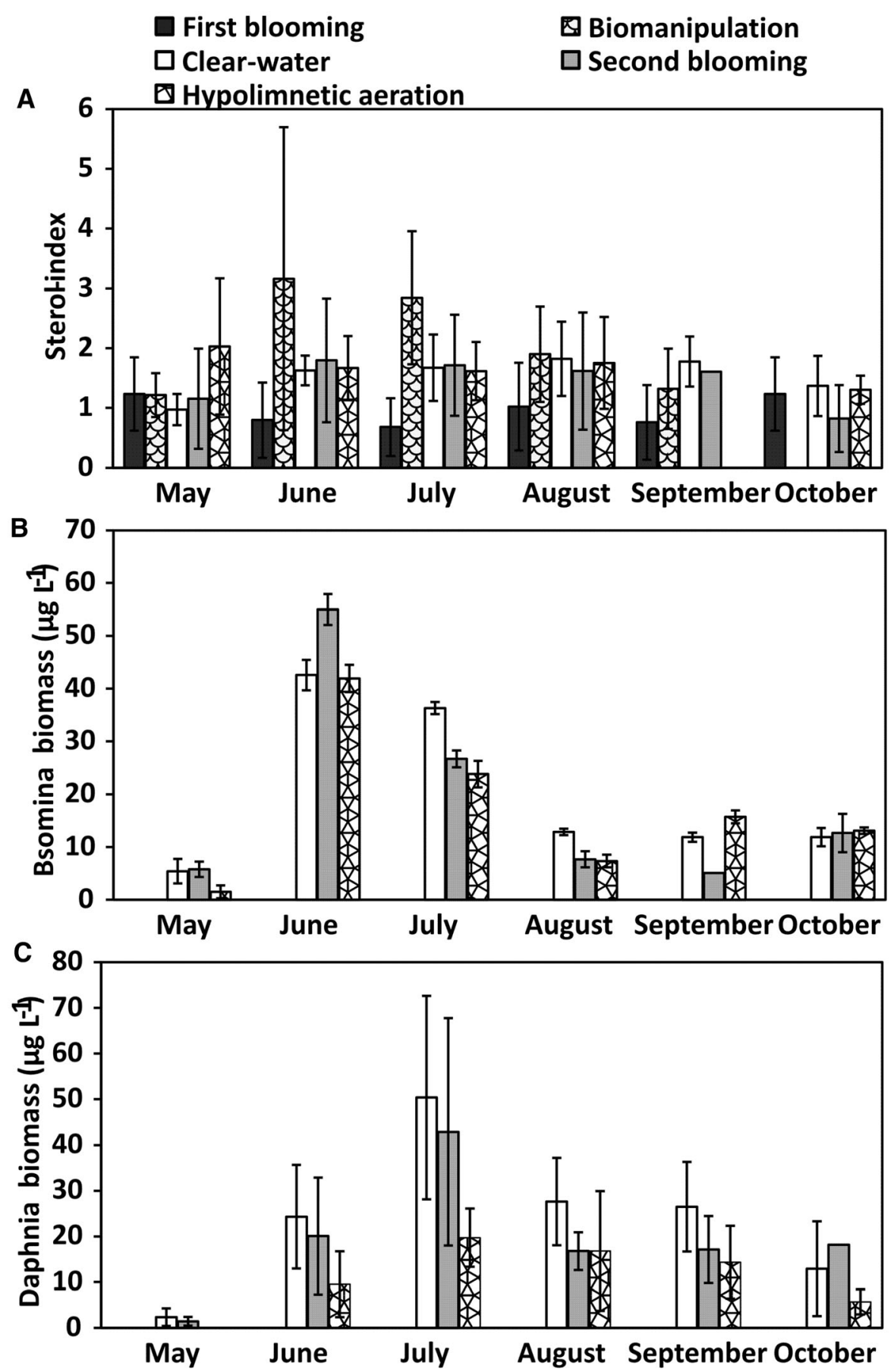

Fig. 4 A Sterol index, $\mathbf{B}$ the biomass of Bosmina $\left(\mu \mathrm{g}^{-1}\right)$ and $\mathbf{C}$ Daphnia during open-water months in different stages. See statistical difference among stages and months from Tables 4 and 5

consideration when judging the outcome of lake restoration. We studied the impacts of two lake management measures, biomanipulation and hypolimnetic aeration, on phytoplankton nutritional value and subsequent correlation with Daphnia and Bosmina biomass. Multivariate analyses differentiated 
Fig. 5 Regression between the total biomass of Daphnia and Bosmina with sterol index (A), the contribution of $\omega-6$ PUFA (B), $\omega-3$ PUFA $(\mathbf{C})$ and the contribution of EPA + DHA (D) from all FA. For sterol $(y=13.11 x+29.37$, $\left.r^{2}=0.36\right)$ and $\omega-6$ PUFA $(y=6.86 x+14.98$, $r^{2}=0.27$ ), the regression was statistically significant and when highest biomass of Daphnia and Bosmina was excluded (black circle) this regression was even stronger $(y=13.95 x+25.16$, $\left.r^{2}=0.52\right)$
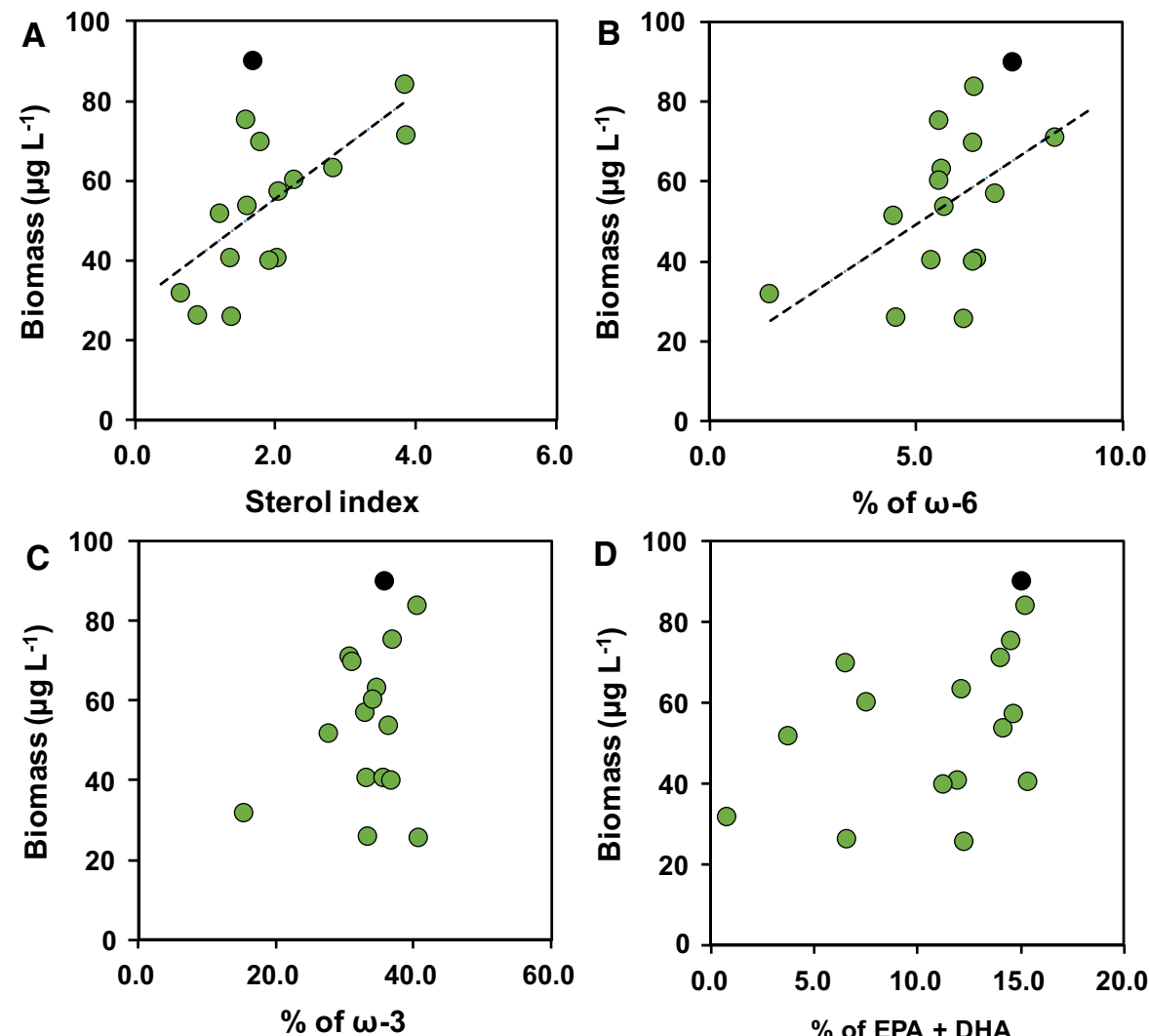

the phytoplankton community structure into four separate clusters. Phytoplankton community structure during the biomanipulation and the hypolimnetic aeration was more similar to that of the first blooming stage than the clear-water stage. These different phases detected with non-metric multidimensional scaling (NMDS) may be useful in future evaluations of lake stages and the direction of the applied restoration acts in Lake Vesijärvi. According to the SIMPER analysis, the cyanobacterial genera Planktothrix, Pseudanabaena, Aphanizomenon and Dolichospermum were characteristic for the first blooming stage. These four genera contributed most to the dissimilarities between phytoplankton community of the first blooming stage and the other stages. This corresponds with the initial observations that described the high biomass of cyanobacteria.

The effectiveness of biomanipulation can be seen in the total absence of cyanobacterial blooms during the clear-water stage, which occurred 1-5 years after the fish removal in Lake Vesijärvi as previously reported from other lakes (Bernes et al., 2015). A previous study explained the success of biomanipulation in Lake Vesijärvi in terms of reduced fish-mediated internal loading, recycling and translocation of nutrients from littoral to pelagial rather than grazing rate of zooplankton (Horppila et al., 1998). However, the zooplankton data of Horppila et al. (1998) did not cover the period before biomanipulation. Later, subfossil evidence showed that the body size of Daphnia and Bosmina increased significantly after the removal of fish (Nykänen et al., 2010), suggesting enhanced control of phytoplankton by zooplankton. As the concentration of TP was similar during the clear-water and the second blooming stage, it cannot explain the occasional blooms of cyanobacteria during the second blooming stage. However, there are multiple other stressors, such as intensified lakeshore building, exceptional weather conditions and hypolimnetic oxygen deficiency which probably contributed to deteriorating water quality (Nykänen et al., 2010; Anttila et al., 2013).

Positive impacts of hypolimnetic aeration on phytoplankton community were not seen, as 
Table 4 Permutational multivariate analysis of variance (PERMANOVA) results for pairwise comparisons of sterol index, the contribution of $\omega-3$ PUFA, $\omega-6$ PUFA, EPA, and DHA, the biomass of Daphnia when stage was used as a factor
For Daphnia biomass, biomanipulation and clear stage was merged as one

\begin{tabular}{|c|c|c|c|}
\hline Unit & Factor (stage) & $t$ & $\mathrm{P}($ perm $)$ \\
\hline \multirow[t]{5}{*}{ Sterol index } & Stage & & \\
\hline & First blooming stage, Second blooming stage & 2.4491 & 0.023 \\
\hline & First blooming stage, Biomanipulation & 5.0782 & 0.001 \\
\hline & First blooming stage, Hypolimnetic aeration & 3.8887 & 0.001 \\
\hline & First blooming stage, Clear stage & 4.1495 & 0.001 \\
\hline \multirow[t]{4}{*}{$\omega-3$ PUFA } & Stage & & \\
\hline & First blooming stage, Biomanipulation & 2.1311 & 0.043 \\
\hline & First blooming stage, Clear stage & 3.3341 & 0.004 \\
\hline & Second blooming stage, Clear stage & 2.0791 & 0.047 \\
\hline \multirow[t]{5}{*}{$\omega-6$ PUFA } & Stage & & \\
\hline & First blooming stage, Biomanipulation & 4.5528 & 0.001 \\
\hline & First blooming stage, Clear stage & 3.9501 & 0.001 \\
\hline & Hypolimnetic aeration, Biomanipulation & 2.7191 & 0.007 \\
\hline & Hypolimnetic aeration, Clear stage & 2.4739 & 0.013 \\
\hline \multirow[t]{8}{*}{ EPA } & Stage & & \\
\hline & First blooming stage, Hypolimnetic aeration & 2.4613 & 0.019 \\
\hline & First blooming stage, Second blooming stage & 2.3383 & 0.015 \\
\hline & First blooming stage, Biomanipulation & 4.6642 & 0.001 \\
\hline & First blooming stage, Clear stage & 6.6758 & 0.001 \\
\hline & Hypolimnetic aeration, Clear stage & 2.4204 & 0.025 \\
\hline & Second blooming stage, Clear stage & 2.0698 & 0.045 \\
\hline & Biomanipulation, Clear stage & 2.1341 & 0.031 \\
\hline \multirow[t]{6}{*}{ DHA } & Stage & 1.7224 & 0.089 \\
\hline & First blooming stage, Hypolimnetic aeration & 2.5415 & 0.013 \\
\hline & First blooming stage, Second blooming stage & 3.2088 & 0.012 \\
\hline & First blooming stage, Biomanipulation & 3.2741 & 0.003 \\
\hline & First blooming stage, Clear stage & 4.5702 & 0.001 \\
\hline & Hypolimnetic aeration, Clear stage & 2.3339 & 0.018 \\
\hline \multirow[t]{3}{*}{ Daphnia } & Stage & & \\
\hline & Clear stage, Hypolimnetic aerotation & 4.0909 & 0.002 \\
\hline & Second blooming stage, Hypolimnetic aerotation & 2.2734 & 0.046 \\
\hline
\end{tabular}

cyanobacterial blooms occurred during the aeration years, in contrast to what was assumed when this restoration measure was launched by lake managers. Planktothrix was the most common cyanobacterial genus, which in fact are tolerant to water-column mixing (Reynolds, 1994) and are shown to increase in abundance when water columns are mixed (Visser et al., 2016). The mechanisms behind this are probably increased hypolimnion temperature, turbulence, and enhanced recycling of $\mathrm{P}$ and organic material (Salmi et al., 2014; Niemistö et al., 2016). Of the Planktothrix species, $P$. agardhii is known to be abundant in turbulent water (Dokulil \& Treubner, 2000). However, some years during the aeration stage were similar to the clear-water stage, which resulted from variation in thermal stratification during the years of mixing. Dispersion analysis showed that phytoplankton community structure was most stable during the clearwater stage. This is mainly because slowly growing large-sized K-strategist species (large cryptophytes, chrysophytes, dinoflagellates and diatoms) are more common in stable and mature environments than faster growing r-strategist species (e.g., many cyanobacteria and small diatoms) that can gain high biomasses (Kilham \& Hecky, 1988; Reynolds, 2006). This is in congruence with our results, since the large bush-like 
Table 5 Permutational multivariate analysis of variance (PERMANOVA) results for pairwise comparisons of sterol index, the contribution of $\omega-3$ PUFA, $\omega-6$ PUFA, EPA, and DHA, the biomass of Bosmina and Daphnia when month was used as a factor

\begin{tabular}{|c|c|c|c|}
\hline Unit & Factors (month) & $t$ & $P($ perm $)$ \\
\hline \multirow[t]{6}{*}{$\omega-3$ PUFA } & Month & & \\
\hline & September, July & 2.2571 & 0.05 \\
\hline & June, August & 2.8635 & 0.006 \\
\hline & June, November & 2.4999 & 0.015 \\
\hline & June, May & 2.2584 & 0.028 \\
\hline & November, May & 2.0434 & 0.05 \\
\hline \multirow[t]{6}{*}{$\omega-6$ PUFA } & Month & & \\
\hline & September, May & 2.3583 & 0.023 \\
\hline & June, July & 2.3068 & 0.025 \\
\hline & June, May & 4.858 & 0.001 \\
\hline & August, May & 3.2509 & 0.003 \\
\hline & July, May & 2.8906 & 0.003 \\
\hline \multirow[t]{6}{*}{ EPA } & Month & & \\
\hline & September, May & 4.6996 & 0.001 \\
\hline & June, May & 3.2699 & 0.002 \\
\hline & August, May & 4.891 & 0.001 \\
\hline & July, May & 4.2419 & 0.002 \\
\hline & May, October & 2.5359 & 0.019 \\
\hline \multirow[t]{10}{*}{ DHA } & Month & & \\
\hline & September, May & 2.2049 & 0.043 \\
\hline & June, November & 2.7934 & 0.006 \\
\hline & June, May & 3.301 & 0.003 \\
\hline & June, April & 7.0094 & 0.001 \\
\hline & August, May & 2.3014 & 0.026 \\
\hline & August, April & 4.1396 & 0.007 \\
\hline & July, May & 2.9027 & 0.006 \\
\hline & July, April & 6.1162 & 0.001 \\
\hline & October, April & 6.3808 & 0.002 \\
\hline \multirow[t]{9}{*}{ Bosmina } & Month & & \\
\hline & May, June & 4.4343 & 0.001 \\
\hline & May, July & 2.929 & 0.01 \\
\hline & June, August & 6.8763 & 0.001 \\
\hline & June, September & 5.813 & 0.001 \\
\hline & June, October & 5.196 & 0.001 \\
\hline & July, August & 4.4944 & 0.001 \\
\hline & July, September & 3.453 & 0.001 \\
\hline & July, October & 3.1022 & 0.003 \\
\hline \multirow[t]{4}{*}{ Daphnia } & Month & & \\
\hline & May, June & 4.0018 & 0.001 \\
\hline & May, July & 4.6069 & 0.002 \\
\hline & May, August & 5.6073 & 0.001 \\
\hline
\end{tabular}

Table 5 continued

\begin{tabular}{llll}
\hline Unit & Factors (month) & $t$ & $P$ (perm) \\
\hline May, September & 6.2988 & 0.001 \\
May, October & 2.7023 & 0.015 \\
June, July & 2.8357 & 0.006 \\
June, October & 2.4372 & 0.028 \\
July, August & 3.0716 & 0.002 \\
July, September & 2.9261 & 0.009 \\
July, October & 4.1756 & 0.003 \\
August, October & 3.1458 & 0.004 \\
\hline
\end{tabular}

colonies forming chrysophyte Dinobryon, the synurophyte Mallomonas, the diatom Asterionella, and the cryptophyte Cryptomonas were most abundant during the clear-water stage, whereas cyanobacteria and the diatom Cyclotella were most abundant during the blooming stages.

The impact of restoration measures on the nutritional value of phytoplankton

In terms of the nutritional value of phytoplankton, non-sterol, non-EPA, and non-DHA-synthesizing phytoplankton taxa dominated during the first blooming stage, which is the typical situation in eutrophic lakes with cyanobacteria blooms (Taipale et al. 2016). Previous studies have shown low availability of physiologically essential EPA and DHA in the seston of eutrophic and hypereutrophic lakes. Positive impact of biomanipulation resulted in high contribution of sterol-, EPA-, and DHA-synthesizing taxa that prevailed during the clear-water stage, similarly as seen in oligotrophic and mesotrophic lakes (Müller-Navarra et al. 2004; Persson et al. 2006; Taipale et al. 2016, 2019). During the biomanipulation period, the contribution of DHA-synthesizing taxa was higher than during any other stages, whereas the contribution of sterol- and EPA-synthesizing taxa did not differ between the clear-water and the second blooming stage due to the high abundance of diatoms. Hypolimnetic aeration did not have a similar positive impact as biomanipulation on phytoplankton community structure, as the contribution of sterol-, EPA-, and DHAsynthesizing taxa was lower than during the clearwater years. 
When summer averages of phytoplankton biomasses were converted to $\omega-3$ and $\omega-6$ PUFA and sterols, the clearest difference was found in the $\omega-6$ PUFA and the sterol index, which were higher during the clear-water stage than during any other stage. Similar differences were not found with $\omega-3$ PUFA, EPA, and DHA when using summer averages, but monthly comparison suggested a positive impact of biomanipulation on their seasonal development during the clear-water stage. Therefore, it may be more beneficial to use monthly averages than to use one value for the whole summer. For example, the contribution of EPA was equally high during spring and fall mixing at each stage due to high diatom biomass. Therefore, the initial situation in the spring was approximately similar during all the years and could have resulted in the development of high biomasses of Daphnia and Bosmina. The availability of EPA in the summer was lowest during the first blooming stage, when EPA contributed only $2 \%$ of all FA. Previous studies have suggested that both EPA and sterols limit Daphnia growth and carbon transfer in systems with high abundance of cyanobacteria (von Elert et al. 2003). Here, monthly averages showed lower availability of sterols and EPA during first blooming stage than in the any other stage. Moreover, the contribution of EPA was higher in the clear-water stage than in any other stage, whereas similar differences in the availability of sterols were not found. Daphnia biomass was higher during biomanipulation and the subsequent clear-water stage than during the hypolimnetic aeration. The difference was greatest in July, when Daphnia biomass was highest during the clear-water stage unlike during other stages. Daphnia biomass was drastically lower in the aeration stage than before. Therefore, it can be assumed that biomanipulation enhanced the availability of EPA for Daphnia, especially in July. One possible reason for the decline in Daphnia biomass during aeration may have been the reduced availability of high-quality food, i.e., the prevalence of non-motile species over motile EPA and DHA-synthesizing taxa as a result of aeration induced mixing of water column. Altogether, it seems that phytoplankton community structure rich in $\omega-3$ and $\omega-6$ PUFA is beneficial for Daphnia and can be considered as one of the desired goals of lake restoration.
Factors and measures influencing on the success of Bosmina and Daphnia

Laboratory experiments have shown that Daphnia can reproduce only in the presence of green algae, cryptophytes, chrysophytes or diatoms (Peltomaa et al., 2017; Taipale et al., 2019). The clutch size of Daphnia can be even 2-4 times higher when feeding on cryptophytes than with chrysophytes, diatoms, or green algae. Cryptophytes contain all essential biomolecules, whereas other phytoplankton taxa are low or lack some biomolecules. Fatty acid mixing modeling of Daphnia diet from different boreal lakes has also shown that Daphnia prefer feeding on cryptophytes (Taipale et al., 2016, 2019) and that a small addition of cryptophytes in their diet can multiply Daphnia clutch size (Taipale et al., 2019). Therefore, successful lake restoration targeting to enhance the biomass of Daphnia should enhance the biomass and the relative contribution of cryptophytes, especially during the summer months. The absolute biomass of cryptophytes was highest during the first blooming stage and biomanipulation and then in the order of clear-water stage $>$ second blooming stage $>$ hypolimnetic aeration. The contribution of cryptophytes was increased by biomanipulation, confirming the positive impact of fish removal on the abundance of cryptophytes (Søndergaard et al., 2012). Even though the abundance of cryptophytes was low during hypolimnetic aeration, the contribution of cryptophytes did not differ statistically from the clear-water stage. This might be a result of stronger stratification during some years of aeration, such as 2013, when mixing was initiated over a month later than usual, because the lake was well stratified with oxygen-rich hypolimnion. Only in late July, the hypolimnion became hypoxic, and aeration was turned on (M. Kotakorpi, pers. com.).

In Lake Vesijärvi, biomanipulation increased the biomasses of Daphnia and Bosmina, most likely because of both bottom-up and top-down regulation. Lower predation pressure can be attributed to larger size of Daphnia (Kuoppamäki et al., manuscript in preparation), and their growth and reproduction rates were enhanced by abundant cryptophytes. When turning cryptophyte biomass into biomolecules, high amounts of amino acids, $\omega-3$ and $\omega-6$ PUFA and sterols were available. The availability of sterols correlated with Bosmina and Daphnia biomass, which 
is typical in eutrophic lakes with cyanobacterial blooms (von Elert et al., 2002; Peltomaa et al., 2017). Sterol index was highest during the biomanipulation period and most likely partly enabled the increase in the biomass of Daphnia. Regression between Bosmina and Daphnia biomass and sterol index showed that year 2001, when their biomass peaked, did not fit to the regression, suggesting other factors besides sterols restricted their biomass. Based on the results obtained in our previous laboratory experiment (Peltomaa et al. 2017), they probably shifted from potential sterol limitation toward amino acid and/or $\omega$-3 PUFA limitation. Martin-Creuzburg et al. (2009) found strong colimitation of sterols and EPA for Daphnia growth and reproduction. Here, we were not able to do quantitative comparison, since only contributions were used in our analyses. Nevertheless, the contribution of $\omega$-3 PUFA including EPA and DHA was high at that time, too, suggesting an important role of these $\omega-3$ PUFA in supporting the growth of cladocerans.

Daphnia biomass decreased during the second blooming stage and the aeration stage, even though phytoplankton community structure or summer averages of EPA and DHA did not suggest such a high decrease. Therefore, some additional factors may have hampered the performance of Daphnia, such as aeration induced turbulence and the loss of the dark, oxygen-poor hypolimnetic refuge from predation by fish, a phenomenon documented as a response to lake mixing (Gauthier et al., 2014; Ruuhijärvi et al., 2020). In our study lake, small-sized smelt (Osmerus eperlanus) built up exceptionally high populations following aeration, and they obviously preyed heavily on Daphnia, evidenced by drastically reduced body size (Ruuhijärvi et al., 2020). Mixing may have also made it difficult for Daphnia to find high-quality diet (Taipale et al., 2019). Explaining the development of Daphnia biomass requires understanding of the availability of EPA and DHA throughout the open-water season. In addition to nutritional quality, the morphology of planktonic algae affects zooplankton grazers. Abundant large colonial and filamentous algae, such as Planktothrix, which increased in biomass during aeration, can hamper the feeding of Daphnia (Gliwicz 2003).

\section{Conclusions}

Our study showed that biomanipulation had a positive impact on the abundance of EPA- and DHA-synthesizing phytoplankton taxa, such as cryptophytes and silica-scaled chrysophytes (synurophytes), which are beneficial food for zooplankton grazers, especially for the keystone species Daphnia. On the other hand, such positive impacts were not seen with hypolimnetic aeration and, rather, this restoration measure seemed to have undesirable effects on both phytoplankton and Daphnia. Our analysis shows that the determination of nutritional value of algae and the contribution of physiologically essential fatty acids is potentially an efficient method for evaluating the success of various restoration practices at the zooplankton-phytoplankton interface.

Acknowledgements The study was funded by the Academy of Finland (Project 311229 MiDAS) awarded to K.V. and Lake Vesijärvi Foundation. Zooplankton studies during the 1990s and early 2000s were done in various projects financed by the Academy of Finland, City of Lahti and the European Union. The authors would like to thank Gabriella Chebli for editing the English of this manuscript.

Funding Open access funding provided by University of Jyväskylä (JYU).

Open Access This article is licensed under a Creative Commons Attribution 4.0 International License, which permits use, sharing, adaptation, distribution and reproduction in any medium or format, as long as you give appropriate credit to the original author(s) and the source, provide a link to the Creative Commons licence, and indicate if changes were made. The images or other third party material in this article are included in the article's Creative Commons licence, unless indicated otherwise in a credit line to the material. If material is not included in the article's Creative Commons licence and your intended use is not permitted by statutory regulation or exceeds the permitted use, you will need to obtain permission directly from the copyright holder. To view a copy of this licence, visit http://creativecommons.org/licenses/by/4.0/.

\section{References}

Ahlgren, G., I.-B. Gustafsson \& M. Boberg, 1992. Fatty acid content and chemical composition of freshwater microalgae. Journal of Phycology 28: 37-50.

Andersen, T., J. Carstensen, E. Hernández-García \& C. M. Duarte, 2008. Ecological thresholds and regimes shifts: 
approaches to identification. Trends in Ecology and Evolution 24: 49-57.

Anttila, S., M. Ketola, K. Kuoppamäki \& T. Kairesalo, 2013. Identification of a biomanipulation-driven regime shift in Lake Vesijärvi: implications for lake management. Freshwater Biology 58: 1494-1502.

Arts, M. T., M. T. Brett \& M. J. Kainz, 2009. Lipids in Aquatic Ecosystems. Springer, New York.

Bernes, C., S. R. Carpenter, A. Gårdmark, P. Larsson, L. Persson, C. Skov, et al., 2015. What is the influence of a reduction of planktivorous and benthivorous fish on water quality in temperate eutrophic lakes? A systematic review. Environmental Evidence 4: 1-28.

Bigelow, N., J. Barker, S. Ryken, J. Patterson, W. Hardin, S. Barlow, C. Deodato \& R.A. Cattolico, 2013. Chrysochromulina sp.: a proposed lipid standard for the algal biofuelindustry and its application to diverse taxa for screening lipid content. Algal Research 2, https://doi.org/10.1016/j. algal.2013.07.001.

Boechat, I., G. Weithoff, A. Krüger, B. Gücker \& R. Adrian, 2007. A biochemical explanation for the success of mixotrophy in the flagellate Ochromonas sp. Limnology and Oceanography 52: 1624-1632.

Burns, C. W., M. T. Brett \& M. Schallenberg, 2011. A comparison of the trophic transfer of fatty acids in freshwater plankton by cladocerans and calanoid copepods. Freshwater Biology 56: 889-903.

Carpenter, S. R., 2003. Regime shifts in lake ecosystems. Ecology Institute, Oldendorf-Luhe, Germany.

Carpenter, S. R., 2008. Phosphorus control is critical to mitigating eutrophication. PNAS 105: 11039-11040.

Cooke, G. D., E. B. Welch, S. A. Peterson \& S. A. Nichols, 2005. Restoration and management of lakes and reservoirs, 3rd ed. Taylor \& Francis, Boca Raton, London.

Dokulil, M. T. \& K. Teubner, 2000. Cyanobacterial dominance in lakes. Hydrobiologia 438: 1-12.

Galloway, A. W. E. \& M. Winder, 2015. Partitioning the relative importance of phylogeny and environmental conditions on phytoplankton fatty acids. PloS ONE 10: e0130053.

Gauthier, J., Y. T. Prairie \& B. E. Beisner, 2014. Thermocline deepening and mixing alter zooplankton phenology, biomass and body size in a whole-lake experiment. Freshwater Biology 59: 998-1011.

Gliwicz, M. 2003. Between hazards of starvation and risk of predation: the ecology of offshore animals. Excellence in Ecology 12, International Ecology Institute, Germany.

Grosbois, G., H. Mariash, T. Schneider \& M. Rautio, 2017. Under-ice availability of phytoplankton lipids is key to freshwater zooplankton winter survival. Scientific Reports 7(1): 11543.

Horppila, J., H. Peltonen, T. Malinen, E. Luokkanen \& T. Kairesalo, 1998. Top-down or bottom-up effects by fish: issues of concern in biomanipulation of lakes. Restoration Ecology 6: 20-28.

Huisman, J., G. A. Codd, H. W. Paerl, B. W. Ibelings, J. M. H. Verspangen \& P. M. Visser, 2018. Cyanobacterial blooms. Nature Reviews Microbiology 16: 471-783.

Jeppesen, E., M. Søndergaard, J. P. Jensen, K. Havens, O. Anneville, L. Carvalho, M. F. Coveney, R. Deneke, M. T. Dokulil, B. Foy, D. Gerdeaux, S. E. Hampton, S. Hilt, K. Kangur, J. Köhler, E. Lammens, T. L. Lauridsen, M.
Manca, R. Miracle, B. Moss, P. No ges, G. Persson, G. Phillips, R. Portielje, S. Romo, C. L. Schelske, D. Straile, I. Tatrai, E. Wille 'n \& M. Winder, 2005. Lakes' response to reduced nutrient loading-an analysis of contemporary data from 35 European and North American long term studies. Freshwater Biology 50: 1747-1771

Jorgensen, S. E., 2001. Water Quality: The Impact of Eutrophication. Lakes and Reservoirs 3: 15-18.

Kairesalo, T. \& K. Vakkilainen, 2004. Lake Vesijärvi and the city of Lahti (southern Finland): comprehensive interactions between the lake and the coupled human community. SILnews, 41, 1-5. Available at: http://www.limnology.org/ news/silnews41.pdf.

Kairesalo, T., S. Laine, E. Luokkanen, T. Malinen \& J. Keto, 1999. Direct and indirect mechanisms behind successful biomanipulation. Hydrobiologia 395: 99-106.

Kilham, P. \& R. E. Hecky, 1988. Comparative ecology of marine and freshwater phytoplankton. Limnology and Oceanography 33: 776-795.

Kozak, A., R. Gołdyn, R. Dondajewska, K. KowalczewskaMadura \& T. Holona, 2017. Changes in phytoplankton and water quality during sustainable restoration of an urban lake used for recreation and water supply. Water 9: 713.

Maileht, K., T. Nöges, P. Nöges, I. Ott, U. Mischke, L. Carvalho, et al., 2013. Water colour, phosphorus and alkalinity are the major determinants of the dominant phytoplankton species in European lakes. Hydrobiologia 704: 115-126.

Martin-Creuzburg, D., E. Sperfeld \& A. Wacker, 2009. Colimitation of a freshwater herbivore by sterols and polyunsaturated fatty acids. Proceedings of the Royal Society B: Biological Sciences 276: 1805-1814.

Martin-Creuzburg, D., S. Oexle, S. \& A. Wacker, 2014. Thresholds for sterollimited growth of Daphnia magna: a comparative approach using 10 different sterols. Journal of Chemical Ecology 40: 1039-1050. https://doi.org/10.1007/ s10886-014-0486-1.

Menden-Deuer, S. \& E. J. Lessard, 2000. Carbon to volume relationships for dinoflagellates, diatoms, and other protist plankton. Limnology Oceanograrphy 45: 569-579.

Müller, B., L. D. Bryant, A. Matzinger \& A. Wüest, 2012. Hypolimnetic oxygen depletion in eutrophic lakes. Environmental Science \& Technology 46: 9964-9971.

Müller-Navarra, D. C., M. T. Brett, S. Park, S. Chandra, A. P. Ballantyne, E. Zorita \& C. R. Goldman, 2004. Unsaturated fatty acid content in seston and tropho-dynamic coupling in lakes. Nature 427: 69-72.

Niemistö, J., P. Tamminen, P. Ekholm \& J. Horppila, 2012. Sediment resuspension: rescue or downfall of a thermally stratified eutrophic lake? Hydrobiologia 686: 267-276.

Niemistö, J., P. Köngäs, L. Härkönen \& J. Horppila, 2016. Hypolimnetic aeration intensifies phosphorus recycling and increases organic material sedimentation in a stratifying lake: effects through increased temperature and turbulence. Boreal Environmental Research 21: 571-587.

Nykänen, M., T. Malinen, K. Vakkilainen, M. Liukkonen \& T. Kairesalo, 2010. Cladoceran community responses to biomanipulation and re-oligotrophication in Lake Vesijärvi, Finland, as inferred from remains in annually laminated sediment. Freshwater Biology 55: 1164-1181.

Peltomaa, E. T., S. L. Aalto, K. M. Vuorio \& S. J. Taipale, 2017. The importance of phytoplankton biomolecule availability 
for secondary production. Frontiers Ecology and Evolution 5: 128 .

Peltomaa, E., H. Hällfors \& S. J. Taipale, 2019. Comparison of diatoms and dinoflagellates from different habitats as sources of PUFAs. Marine Drugs 17: 233.

Persson, J. M., M. T. Brett, T. Vrede \& L. Ravet, 2007. Food quantity and quality regulation of trophic transfer between primary producers and a keystone grazer (Daphnia) in pelagic freshwater food webs. Oikos 116: 1152-1163.

Reynolds, C. S., 1994. The long, the short and the stalled: on the attributes of phytoplankton selected by physical mixing in lakes and rivers. Hydrobiologia 289: 9-21.

Reynolds, C. S., 1998. What factors influence the species composition of phytoplankton in lakes of different trophic status? Hydrobiologia 369(370): 11-26.

Reynolds, C. S., 2006. Ecology of Phytoplankton. Cambridge University Press, Cambridge.

Ruuhijärvi, J., T. Malinen, K. Kuoppamäki, P. Ala-Opas \& M. Vinni, 2020. Responses of food web to hypolimnetic aeration in Lake Vesijärvi. Hydrobiologia. https://doi.org/10. 1007/s10750-020-04319-6(0123456(2).

Salmi, P., I. Malin \& K. Salonen, 2014. Pumping of epilimnetic water into hypolimnion improves oxygen but not necessarily nutrient conditions in a lake recovering from eutrophication. Inland Waters 4: 425-434.

Schneider, T., G. Grosbois, W. F. Vincent \& M. Rautio, 2017. Saving for the future: Pre-winter uptake of algal lipids supports copepod egg production in spring. Freshwater Biology 62: 1063-1072.

Slocombe, S. P., Q. Y. Zhang, M. Ross, A. Anderson, N. J. Thomas, Á. Lapresa, et al., 2015. Unlocking nature's treasure-chest: screening for oleaginous algae. Scientific Reports 5: 09844.

Soares, A. T., D. C. da Costa, A. A. H. Vieira \& N. R. Antoniosi Filho, 2019. Analysis of major carotenoids and fatty acid composition of freshwater microalgae. Heliyon 5: e01529.

Søndergaard, M., L. Liboriussen, A. R. Pedersen \& E. Jeppesen, 2008. Lake restoration by fish removal: short- and longterm effects in 36 Danish Lakes. Ecosystems 11: 1291-1305.

Strandberg, U., S. J. Taipale, M. Hiltunen, A. W. E. Galloway, M. T. Brett \& P. Kankaala, 2015. Inferring phytoplankton composition with a fatty acid modeling. Ecosphere 6: 16 .

Taipale, S. J., M. J. Kainz \& M. T. Brett, 2011. Diet-switching experiments show rapid accumulation and preferential retention of highly unsaturated fatty acids in Daphnia. Oikos 120: 1674-1682.

Taipale, S. J., U. Strandberg, E. Peltomaa, A. W. E. Galloway, A. Ojala \& M. T. Brett, 2013. Fatty acid composition as biomarkers of freshwater microalgae: analysis of 37 strains of microalgae in 22 genera and in 7 classes. Aquatic Microbial Ecology 71: 165-178.

Taipale, S. J., K. Vuorio, U. Strandberg, K. K. Kahilainen, M. Järvinen, M. Hiltunen, E. Peltomaa \& P. Kankaala, 2016a. Lake eutrophication and brownification downgrade availability and transfer of essential fatty acids for human consumption. Environmental International 96: 156-166.

Taipale, S. J., M. Hiltunen, K. Vuorio \& E. Peltomaa, 2016b. Suitability of phytosterols alongside fatty acids as chemotaxonomic biomarkers for phytoplankton. Frontiers in Plant Science 7: 212.

Taipale, S. J., S. L. Aalto, A. W. E. Galloway, K. Kuoppamäki, P. Nzobeuh \& E. Peltomaa, 2019. Eutrophication and browning influenceon Daphnia nutritional ecology. Inland Waters. https://doi.org/10.1080/20442041.2019.1574177.

Thornton, J. A., W. R. Harding, M. Dent, R. C. Hart, H. Lin, C. L. Rast, W. Rast, S.-O. Ryding \& M. Slawski, 2013. Eutrophication as w 'wicked' problem. Lakes \& Reservoirs: Research and Management 18: 298-316.

Triest, L., I. Stiers \& S. Van Onsem, 2015. Biomanipulation as a nature-based solution to reduce cyanobacterial blooms. Aquatic Ecology 50: 461-463.

Vakkilainen, K., Kairesalo, T., Hietala, J., Balayla, D., Bécares, E., van de Bund, W., van Donk, E., Fernández-Aláez, M., Gyllström, M., Hansson, L.-A., Miracle, M. R., Moss, B., Romo, S., Rueda, J. \& Stephen, D. 2004. Response of zooplankton to nutrient enrichment and fish in shallow lakes: a pan-European mesocosm experiment. - Freshwater Biology 49: 1619-1632.

Visser, P. M., B. W. Ibelings, M. Bormans \& J. Huisman, 2016. Artificial mixing to control cyanobacterial blooms: a review. Aquatic Ecology 50: 423-441.

Volkman, J. K., S. M. Barrett \& S. I. Blackburn, 1999. Fatty acids and hydroxy fatty acids in three species of freshwater Eustigmatophytes. Journal of Phycology 35: 1005-1012.

von Elert, E., 2002. Determination of limiting polyunsaturated fatty acids in Daphnia galeata using a new method to enrich food algae with single fatty acids. Limnology and Oceanography 47: 1764-1773.

von Elert, E. \& D. Martin-Creuzburg, 2009. Good food versus bad food: the role of sterols and polyunsaturated fatty acids in determining growth and reproduction of Daphnia magna. Aquatic Ecology 43: 943-950.

von Elert, E., D. Martin-Creuzburg \& J. R. Le Coz, 2002. Absence of sterols constrains carbon transfer between cyanobacteria and a freshwater herbivore (Daphnia galeata). Proceedings of the Royal Society B: Biological Sciences 270: 1209-1214.

Vuorio, K., N. Kotamäki \& M. Järvinen, 2020. Phosphorus thresholds for bloom-forming cyanobacterial taxa in northern European lakes. Hydrobiologia. https://doi.org/ 10.1007/s10750-019-04161-5.

Watson, S. B., W. McCauley \& J. A. Downing, 1997. Patterns in phytoplankton taxonomic composition across temperate lakes of differing nutrient status. Limnology and Oceanography 42: 487-495.

Webb, D. J., R. D. Robarts \& E. E. Prepas, 1997. Influence of extended water column mixing during the first 2 years of hypolimnetic oxygenation on the phytoplankton community of Amisk Lake, Alberta. Canadian Journal of Fisheries and Aquatic Sciences 54: 2133-2145.

Publisher's Note Springer Nature remains neutral with regard to jurisdictional claims in published maps and institutional affiliations. 